\title{
Effect of Arbuscular Mycorrhiza Fungi Inoculation on Growth and Uptake of Mineral Nutrition in Ipomoea aquatica
}

\author{
MILTON HALDER $^{1 *}$, P.P DHAR ${ }^{5}$, A.S.M MUJIB ${ }^{2}$, \\ MUHAMMAD SHAHJALAL KHAN ${ }^{3}$, J.C. JOARDAR ${ }^{4}$ and SAMINA AKHTER ${ }^{1}$
}

'BCSIR Laboratories Chittagong, Chittagong Cantonment-4220, Bangladesh.

${ }^{2}$ Cox's Bazar Government Women College, Bangladesh.

${ }^{3}$ Green Solutions Ltd. Bangladesh.

${ }^{4}$ Soil Science Discipline, Khulna University, Khulna-9208, Bangladesh.

${ }^{5}$ King Saud University, Kingdom of Saudi Arabia.

http://dx.doi.org/10.12944/CWE.10.1.08

(Received: Feburary 12, 2015; Accepted: April 02, 2015)

\begin{abstract}
A green house experiment was conducted to investigate the effect of arbuscular mycorrhiza inoculation on plant growth and uptake of mineral nutrition in Ipomoea aquatica considering the objective of using environmental friendly biofertilizer instead of chemical fertilizer. A common leafy vegetable plant Ipomoea aquatica was grown with mycorrhiza and without mycorrhiza for 42 days. After harvesting the plants were analyzed for mineral nutrition concentration. Plant fresh weight, dry weight, macronutrient $(\mathrm{P}, \mathrm{K}, \mathrm{Mg}, \mathrm{Na})$, micronutrient $(\mathrm{Fe}, \mathrm{Mn}, \mathrm{Zn})$ concentration was higher in arbuscular mycorrhiza inoculated plant than non-mycorrhiza inoculated plant. For sustainable agriculture, introducing biofertilizer by using arbuscular mycorrhiza inoculation would be one of the most efficient techniques for replacing chemical fertilizer to meet the nutrient deficiency in nutrient deficient soils of Bangladesh.
\end{abstract}

Key words: Mycorrhiza, Biofertilizer, Macro-nutrient, Micro-nutrient, Concentration.

\section{INTRODUCTION}

Horticultural cultivation is becoming a widespread in the south-east region of Bangladesh. Soils in this region have high levels of sand that cause $\mathrm{P}, \mathrm{Zn}$, and $\mathrm{Mn}$ deficiency. Increased use of chemical fertilizers to improve these deficiencies can adversely affect food chain, human health and the environment. A reduction of the fertilizers input together with selecting cultivars and species better adapted to these constrains is necessary to increase the sustainability of crop production. Arbuscular Mycorrhizal Fungi (AMF) is widespread throughout the world and found in the majority of terrestrial ecosystems (Smith, S.E. and D.J. Read. 2008). AMF can be integrated in soil management to achieve low-cost sustainable agricultural systems. AMF can reduce soil erosion by bringing together micro aggregates of soil particles to form macro aggregates (Miller, R.M. and J.D. Jastrow. 1994). They are the obligate symbionts that can improve plant growth by up taking $\mathrm{P}$ and help to absorb $\mathrm{N}, \mathrm{K}, \mathrm{Ca}, \mathrm{S}, \mathrm{Cu}$, and Zn (Jiang, W. et al., 2013); produce glomalin (Guo, H. et al., 2012); increasing resistance to pests and soil borne diseases (AL-Karaki G.N., 2006); enhance the salt tolerance (Evelin, H. et al., 2009); heavy metal sequestration (Tonin, C.P. et al., 2001) etc. AMF are especially important for sustainable farming systems because AMF are efficient when nutrient availability is low and when nutrients are bound to soil particles and organic matter. Agricultural plants can benefit from AMF, including maize, potato, sunflower, wheat etc especially under some conditions where concentration of nutrient availability is limiting factor for plant growth. Cagras S. et al. (2000) used G. mosseae and $G$. fasciculatum mycorrhizae spores 
to inoculate cucumber plants under sterile and nonsterile conditions in Çukurova region (Turkey) and found that inoculated plants had a higher uptake of P, Zn and Mn. I. Ortas (2010) observed that AMF infection significantly improve cucumber seedling, yield of fruit, concentrations of Zinc and Phosphorous in shoot. Mycorrhizal inoculation of cucumber could increase seedling quality and reduce the quantity of fertilizer application, to achieve similar yields to non-inoculated plants (I. Ortas, 2008). J. Beltrano et al. (2013) reported that interactions between salinity, phosphorous and mycorrhiza in pepper plants were significant for leaf area, root and shoot dry mass. They also showed that non-mycorrhizal plants accumulates lower $\mathrm{K}$, proline content and $\mathrm{P}$ compared to mycorrhizal plants. Ipomoea aquitica $\mathrm{L}$. is a climbing herbaceous plant under the family of Convolvulaceae, a semiaquatic, tropical plant.
Ipomoea aquitica L. is used as a common vegetable in Bangladesh for its tender shoots and leaves which forms symbiotic relation with arbuscular mycorrhiza and have a positive effect on plant growth under controlled experimental conditions (Anwesha M. Bhaduri and M. H. Fulekar, 2012). Junli Hu et al. (2013) reported that AMF with I. aquatica has played key roles in $\mathrm{P}$ mobilization and $\mathrm{Cd}$ stabilization for intercropping system, and it is sustainable and valuable for postharvest soils. Anwesha and Fulekar (2012) showed that due to symbiosis relationship between AMF and plant, I. aquatica is viable in moderately $\mathrm{Cd}$ contaminated soil. In this work we attempted to assess the effects of AMF inoculation on the growth, mineral nutrient uptake and yield under greenhouse conditions with the objective of substituting partially or completely the heavy fertilizer application.

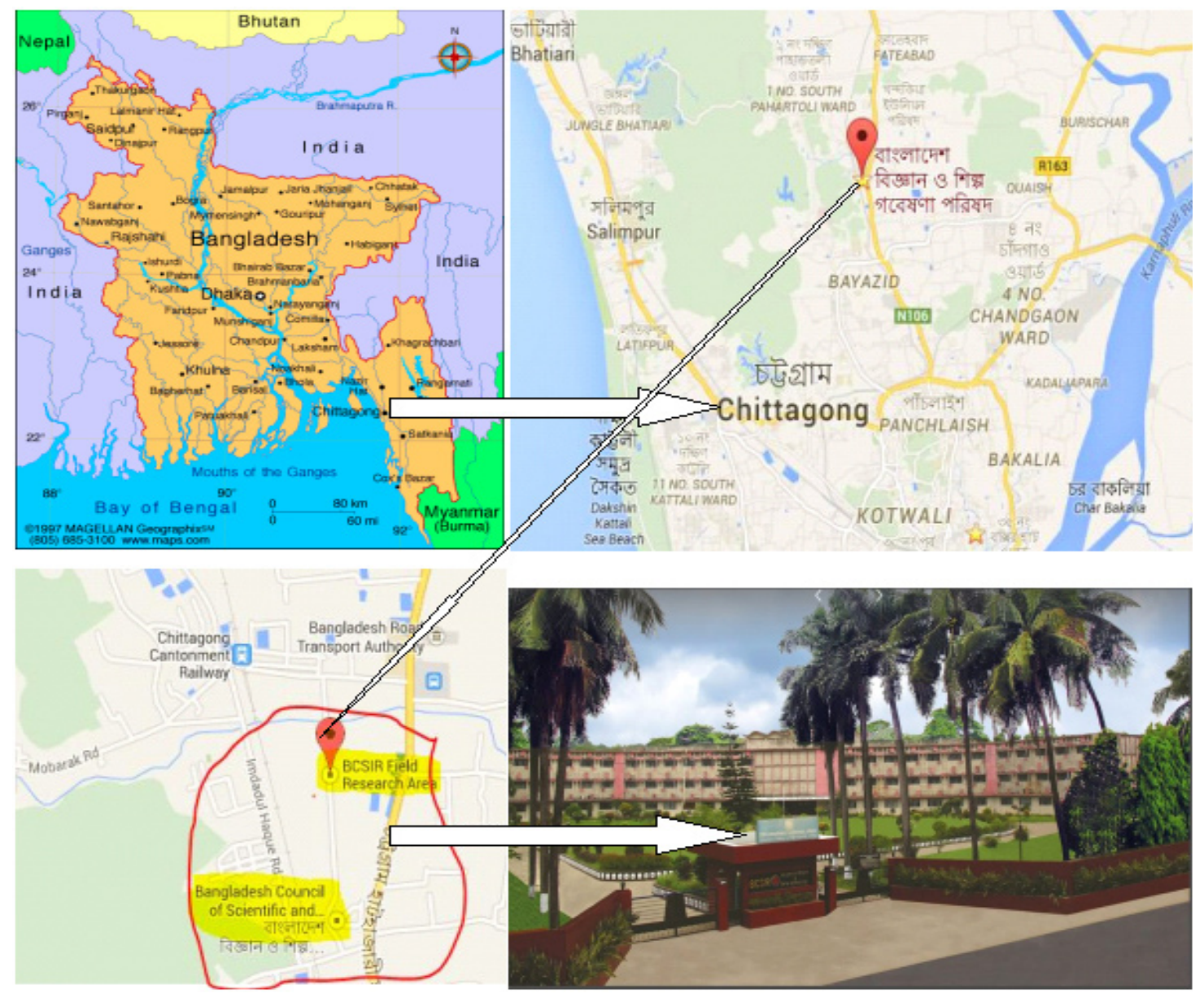

Chittagong BCSIR Laboratories with research field, Bangladesh 


\section{MATERIALS AND METHODS}

\section{Experimental Area}

BCSIR laboratory Chittagong is a government research organization under the umbrella of Ministry of Science and Technology, People's Republic of Bangladesh. Chittagong BCSIR is specialized for research on medicinal, aromatic and vegetable plants. It is situated at $22^{\circ} 24^{\prime} 35.4^{\prime \prime} \mathrm{N}$ $91^{\circ} 49^{\prime} 00.6$ " in the south-eastern part of Bangladesh, with an area of approximately 100 acres. More than 1600 species of medicinal plants also including some vegetables are being grown in the campus. Experimental set up area of Chittagong BCSIR Laboratories is presented in below figure 1 .

\section{Experimental Design}

The pot experiment was carried out under green house condition by following Complete Randomize Design (CRD). The experiment was conducted at Soil Management and Agronomical Research Division in Bangladesh Council of Scientific and Industrial Research (BCSIR), Chittagong, Bangladesh.

\section{Soil sample collection and preparation}

The soil was collected from experimental areas of Soil Management and Agronomical

Table 1: Characteristics of the soil used in pot experiments under glass house condition.

\begin{tabular}{ll}
\hline Parameters & Result \\
\hline Sampling site & BCSIR agricultural field \\
GPS reading of & $22^{\circ} 24^{\prime} 35.2^{\prime \prime} \mathrm{N} 91^{\circ} 48^{\prime} 59.7^{\prime \prime} \mathrm{E}$ \\
the sampling site & \\
Soil Texture & Sandy loam \\
pH & 5.7 \\
EC & $0.75 \mathrm{mS} / \mathrm{m}$ \\
OM & $1.94 \%$ \\
CEC & $19.30 \mathrm{meq} / 100 \mathrm{~g}$ soil \\
Available N & $0.045 \%$ \\
Available P & $17.2 \mathrm{mg} / \mathrm{kg}$ \\
Available $\mathrm{K}$ & $77.24 \mathrm{mg} / \mathrm{kg}$ \\
Available S & $46.69 \mathrm{mg} / \mathrm{kg}$ \\
Available $\mathrm{Fe}$ & $0.02 \%$ \\
Available $\mathrm{Na}$ & $43.7 \mathrm{mg} / \mathrm{kg}$ \\
Available $\mathrm{Ca}$ & $270 \mathrm{~kg} / \mathrm{kg}$ \\
Available $\mathrm{Mg}$ & $0.061 \%$ \\
\hline
\end{tabular}

Research Division of BCSIR, Chittagong. The soils were grinding, air-dried, and sieved through a $2-\mathrm{mm}$ sieve for cultivation of vegetables in pot. The properties of the soil used in green house experiment has been given in Table 1.

\section{Pot collection and preparation}

A total of ten plastic pots of 1-kg size were collected from the local market. The pot was filled with previously collected soil. Five plastic pots were filled with sterilized soil at $121^{\circ} \mathrm{C}$ temperature, 15 PSI, 24 hours. Other five plastic pots were filled with 2 $\mathrm{mm}$ sieved soil from rhizosphere of Acacia mangium which is highly Mycorrhizal colonize (Dhar, P.P., and Mridha, M. A. U. 2012). Additional spores were also isolated and collected from rhizosphere soil by wet sieving and decanting method (Gerdemann JW and Nicolson TH. 1963) and were added to the experimental pots.

\section{Plant cultivation}

Seeds of Ipomoea aquitica were collected from local market and sterilize by $70 \%$ alcohol. Nine to ten seeds of Ipomoea aquitica were sown in each plastic pot. After 15 days from seed sowing, thinning was done keeping only 4 plants in each pot.

\section{Determination of root colonization}

Root sample of each plant rhizosphere was collected. Then the fresh root samples were washed by distilled water and preserved in 5\% formalin. Roots preserved in $5 \%$ formalin were then washed well to remove the formalin and chopped into $1 \mathrm{~cm}$ pieces. Clean root samples were kept in

Table 2: Pearson Correlation co-efficient among the macro and micro nutrients of plant cultivated with mycorrhiza inoculation.

\begin{tabular}{lccccccc}
\hline \multicolumn{1}{r}{$\mathbf{N a}$} & $\mathbf{K}$ & $\mathbf{M g}$ & $\mathbf{F e}$ & $\mathbf{P}$ & $\mathbf{M n}$ & $\mathbf{Z n}$ \\
\hline $\mathrm{Na}$ & 1 & .387 & .266 & .614 & -.026 & $-.923^{*}$ & .537 \\
$\mathrm{~K}$ & & 1 & -.759 & $.936^{*}$ & .624 & -.608 & $.958^{*}$ \\
$\mathrm{Mg}$ & & 1 & -.593 & -.494 & -.050 & -.646 \\
$\mathrm{Fe}$ & & & 1 & .342 & -.712 & $.955^{*}$ \\
$\mathrm{P}$ & & & & 1 & -.360 & .522 \\
$\mathrm{Mn}$ & & & & & 1 & -.708 \\
$\mathrm{Zn}$ & & & & & & 1 \\
\hline
\end{tabular}

* Correlation is significant at the 0.05 level 
$10 \% \mathrm{KOH}$ solution for $10 \mathrm{~min}$ at $85^{\prime \prime} 90^{\circ} \mathrm{C}$ and deeply pigmented roots were treated with $10 \% \mathrm{H}_{2} \mathrm{O}_{2}$ at room temperature for $10 \mathrm{~min}$, stained with $0.05 \%$ aniline blue solution at $90^{\circ} \mathrm{C}$ for $90 \mathrm{~min}$, and then stored in glycerol solution (Phillips, J.M. \& Hayman, D.S. 1970) with some modifications. A total of 100 segments from each species were examined. Roots segments were observed by a compound microscope at $10 \times 10$ magnification. Percent root colonization was calculated (Dhar, P.P., and Mridha, M. A. U. 2012). The root colonization was calculated by using following formula.

Root colonization $(\%)=\frac{\text { Number of AM positive segments }}{\text { Total number of segments observed }} \times 100$

\section{Plant harvesting and processing}

Ipomoea aquitica was the selected plant for the experiment. After harvesting the plants, adhering soil particles was cleared, washed with distilled water to ensure removal of dust particles from plants. Samples were then dried in oven at $60 \pm 5^{\circ} \mathrm{C}$ for 48 hours, grinding and sifted through a $0.2-\mathrm{mm}$ sieve, and stored for further analysis.

\section{Sample preparation and analysis}

The plant samples were digested with a mixture of concentrated nitric acid and perchloric acid. The soil sample was digested with aqua regia $\left[\mathrm{HCl}: \mathrm{HNO}_{3}, 3: 1,(\mathrm{v} / \mathrm{v})\right]$. The digested plant samples were analyzed for $\mathrm{Mn}, \mathrm{Zn}, \mathrm{Fe}, \mathrm{Cu}$ and $\mathrm{Mg}$ by employing an atomic absorption spectrophotometer (Thermo Scientific iCE 3000 Series Atomic Absorption Spectrometer) according to the previously published protocols (Milton et al., 2014). Soil available K, Ca, $\mathrm{Na}$, and plant total $\mathrm{K}, \mathrm{Ca}, \mathrm{Na}$ were determined by using Flame photometer by following the prescribed laboratory methods (Jackson, 1973). Plant P and soil available S, P was also determined by using UV spectrophotometer, Shimadzu-1800 (Huq and Alam, 2005). Reagent blanks and internal standards were used to ensure the accuracy and precision of the analyses.

\section{Statistical Analyses}

The results were expressed as the averages of five replications. The data were subjected to ANOVA for individual nutrients and weight. Differences between means were statistically analyzed using Tukey's test $(p<0.05)$ performed with the SAS 6.0. Parson co efficient of correlation $(p<0.01,0.05)$ was also calculated by using SPSS 16.0.

\section{RESULTS AND DISCUSSIONS}

\section{Effects of mycorrhizal colonization on Ipomoea aquatica weight}

The fresh weight of mycorrhiza inoculated plants was higher than that of non inoculated (control) plants (Figure 1). The average fresh weight

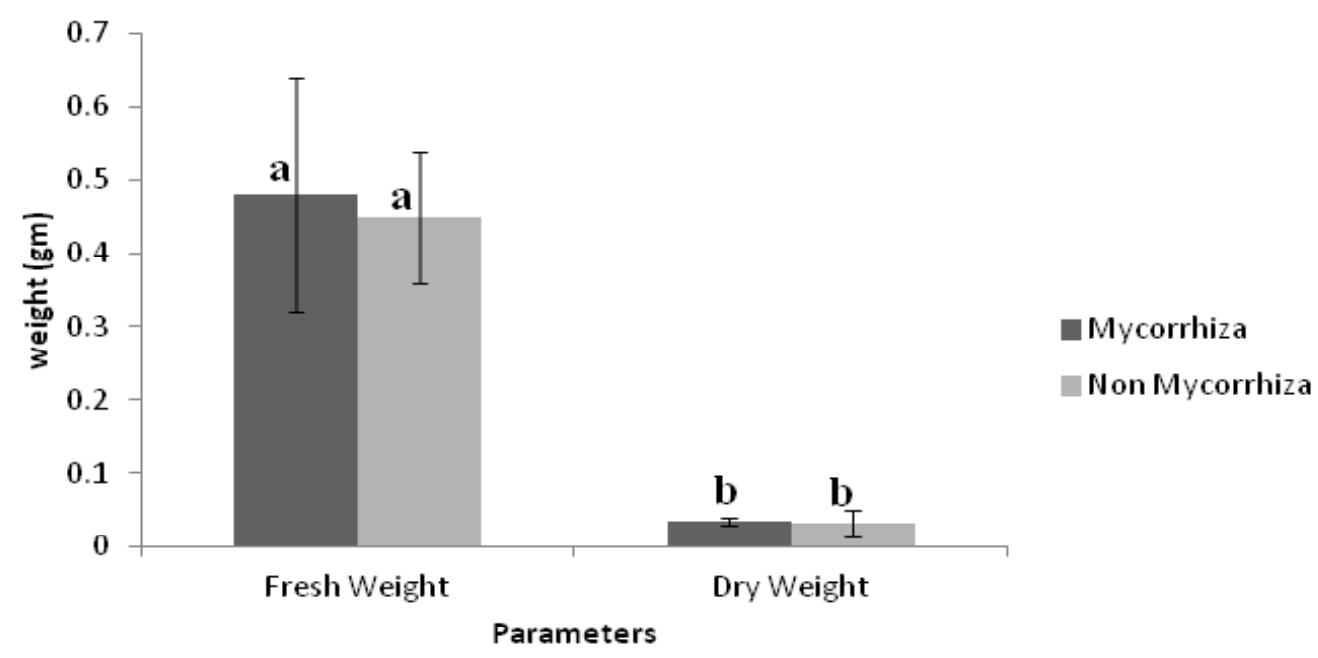

Fig. 1: Effects of mycorrhizal inoculation on the growth of Ipomoea aquatica. Error bars indicate standard deviation (SDs). Mean values followed by the different letters are significantly different $(P<0.05)$ and same letter are not significantly different $(P<0.05)$. 
of mycorrhiza treatment plants was $0.48 \pm 0.16 \mathrm{gm}$ whereas the fresh weight of control plants was $0.45 \pm 0.09 \mathrm{gm}$. Similarly to the fresh weight, the dry weight of treatment plants $(0.034 \pm 0.005)$ was similar to the control plants $(0.032 \pm 0.018 \mathrm{gm})$. There was no significant $(p<0.05)$ differences between the plant weight of mycorrhiza inoculated plants and non-mycorrhizal infected plants. Tabassum et al.
(2011) showed that the AMF infection significantly affects the growth of infected plants compared to non infected plants.

\section{Effects of AMF colonization on macronutrient} accumulation in Ipomoea aquatica

The effect of mycorrhizal funzi on the concentration of macro nutrients $(\mathrm{P}, \mathrm{K}, \mathrm{Mg})$ and

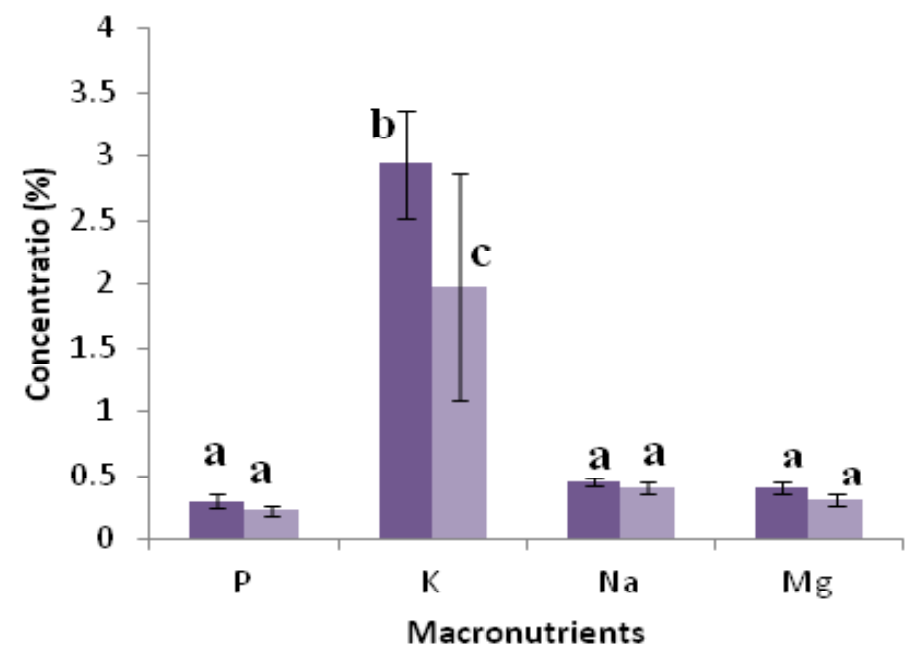

Fig. 2: Effects of mycorrhizal fungi colonization on macro nutrient concentration in Ipomoea aquatica. Error bars represent the standard deviations (SDs). Different letters on bars indicate the significant difference $(P<0.05)$. Means followed by the same letter are not significantly different $(P$ $<0.05)$.

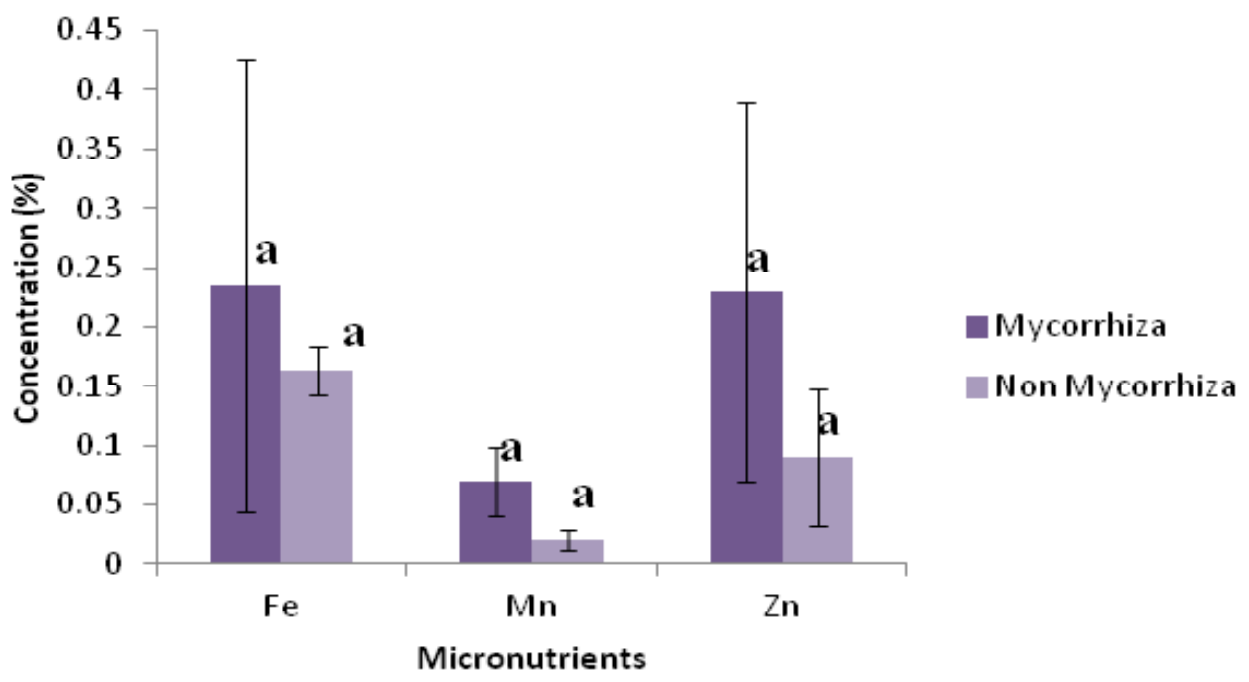

Fig. 3: Effects of mycorrhizal fungi inoculation on micro nutrient concentration in Ipomoea aquatica. Error bars represent the standard deviations (SDs). Means followed by the same letter are not significantly different $(P<0.05)$. 
secondary nutrients $\mathrm{Na}$ in plant part are shown in Figure 2. $\mathrm{P}$ concentration of fungi treated plants was $0.3 \pm 0.05 \%$ and in non treated plants, the concentration was $0.23 \pm 0.04 \%$. So, $P$ concentration was increased due to application of mycorrhizal fungi. One of the major effects of mycorrhizal fungi inoculation in plants is the increase of phosphorus absorption ability, by the direct activity of the extra matricial mycelium that allows the volume exploration of soil. In this process, the AMF make up another chance in the process of up taking nutrients for the plants from soil, particularly phosphorus (Y. Carreon-Abud et al., 2003). The present study agrees with the findings of Almagrabi O. A. and Abdelmoneim T. S. (2012). Potassium concentration was highest in fungi inoculated plants than non inoculated plants (Figure 2). K concentration was $2.94 \pm 0.42 \%$ in fungi treated plants and in control plants the concentration was $1.97 \pm 0.89 \%$. Mg and $\mathrm{Na}$ concentration was more or less similar in fungi

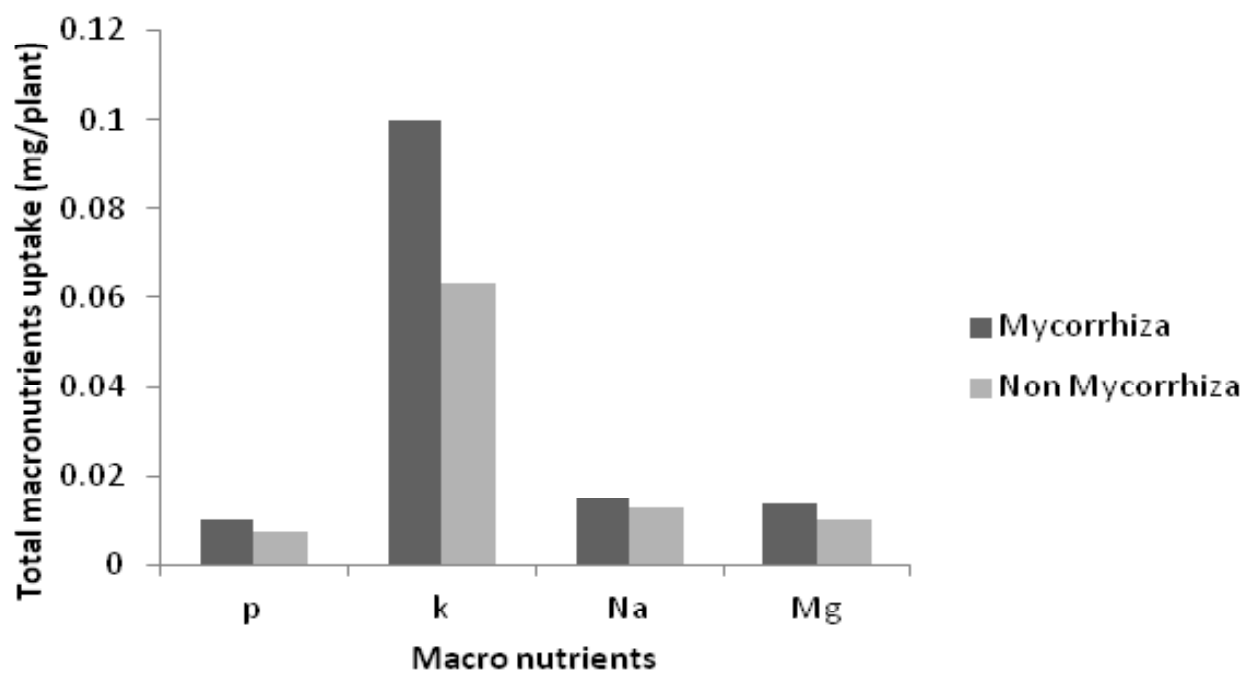

Fig. 4: Effects of AMF infection on macro nutrients uptake in Ipomoea aquatica under pot experiment in green glass house condition.

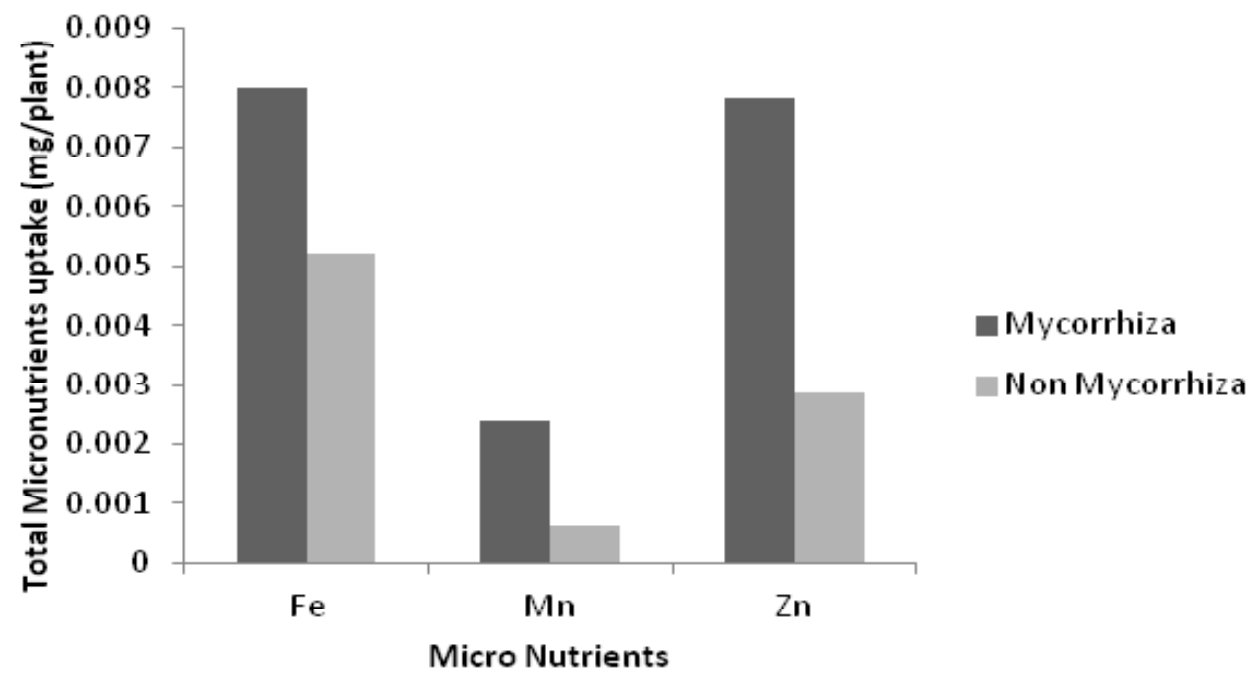

Fig. 5: Effects of mycorrhizal infection on micro nutrients uptake from soil in Ipomoea aquatica under pot experiment in green house condition of BCSIR. 
treated plants and control plants. Mycorrhizal fungi can improve absorption of phosphorus (Jiang, W et al., 2013), potassium and magnesium (Liu A. et al., 2002). Our results are also supported by research of Singh et al. (2004), reported that nutrient uptake of mycorrhizal plants was higher when compared with non-mycorrhizal one. Statistically $\mathrm{Na}$ and $\mathrm{K}$ accumulation in mycorrhiza inoculated plants was significantly $(p<0.05)$ correlated with $\mathrm{Mn}$ and $\mathrm{Fe}, \mathrm{Zn}$ respectively has been shown in table 2 .

\section{Effects of AMF colonization on micronutrient accumulation in Ipomoea aquatica}

The application of mycorrhizalfunzi inoculation also effects the concentration of $\mathrm{Fe}$, $\mathrm{Mn}$ and $\mathrm{Zn}$ in plants (Figure 3 ). Mn percentage in mycorrhizal fungi treated plants $(0.07 \pm 0.029)$ was three times more than that of control plant concentration $(0.02 \pm 0.009)$. Whereas the $\mathrm{Zn}$ percentage was almost double than that of control plants (Figure 3). Fe concentration was not highly differed as like as $\mathrm{Mn}$ and $\mathrm{Zn}$ from inoculated plants to non inoculated plants (Figure 3). Similar result was also reported by some other researchers, (Tabassum Yaseen et al., 2011). Statistically Fe concentration in mycorrhiza inoculated plant significantly ( $r=0.995^{*}$, $\mathrm{p}<0.05)$ correlated with $\mathrm{Zn}$ accumulation in plants. But Milton et al., 2014 showed that $Z n$ concentration was decreased with application of Fe dust due to the antagonistic effect in Ipomoea aquatica.

\section{Effects of AMF infection on macro nutrient uptake}

Among the measured macro nutrients $\mathrm{K}$ uptake was highest compared to other macro nutrients uptake followed by $\mathrm{Na}$ and $\mathrm{Mg}$ for both the cases of mycorrhiza treated and non-treated plants. Least amount of $\mathrm{P}$ uptake was observed (treated with mycorrhiza as $0.01 \mathrm{mg} /$ plant and untreated as $0.007 \mathrm{mg} /$ plant). All micro nutrients uptake values for micorrhiza treated plants were more than that of control plants (Figure 4). In mycorrhiza inoculated plants $\mathrm{Na}$, Mg uptake was $0.015 \mathrm{mg} /$ plant, 0.014 $\mathrm{mg} /$ plant higher than control plants as $0.013 \mathrm{mg} /$ plant and $0.01 \mathrm{mg} /$ plant respectively. Our findings are supported by the work of Tabassum Yaseen et al. (2011) who showed that nutrient uptake of AMF infected plants higher compared to non-AMF infected plants.

\section{Effects of AMF infection on micro nutrient uptake}

All determined micronutrients uptake in AMF treated plants were higher than control plants (without AMF) (Figure 5). The uptake of micro nutrients like as $\mathrm{Fe}, \mathrm{Mn}, \mathrm{Zn}$ was $0.24,0.07,0.23$ $\mathrm{mg} /$ plant in case of mycorrhiza infection but for non infected plant the uptake was 0.16, 0.02, $0.09 \mathrm{mg} /$ plant respectively. AMF have been also shown for betterment of immobile soil nutrients uptake such as P, Zn and Cu (Jiang, W et al., 2013; Liu A et al., 2002).

\section{CONCLUSION}

Mycorrhizal colonization in plant root improves mineral nutrients uptake and plant growth. Macro nutrients concentration and uptake as well as micro nutrients concentration and uptake is higher in mycorrhizal inoculated plant than non mycorrhizal inoculated plant which may be an efficient strategy to utilize environment friendly biofertilizer instead of chemical fertilizer.

\section{ACKNOWLEDGEMENT}

This research work was contended in BCSIR laboratory Chittagong, Bangladesh. The authors would like to give heartiest thanks to the Director and all other staff of BCSIR. The authors also acknowledge the Soil Science Laboratory of BCSIR.

\section{REFERENCES}

1. Almagrabi O. A. and Abdelmoneim T. S. Using of Arbuscular Mycorrhizal Fungi to Reduce the Deficiency Effect of Phosphorous Fertilization on Maize Plants (Zea mays L.). Life Sci J, 9(4):1648-1654 (2012).

2. Anwesha M. Bhaduri and M. H. Fulekar,
Assessment of arbuscular mycorrhizal fungi on the phytoremediation potential of Ipomoea aquatica on cadmium uptake, 3 Biotech. 2(3): 193-198 (2012).

3. Cagras S., Sari N., Ortas I., The effects of vesicular-arbuscular mycorrhizae on the plant 
growth and nutrient uptake of cucumber. Turk J Agric Forest 24:571-578 (2000).

4. Dhar, P.P., and Mridha, M. A. U. Arbuscular mycorrhizal associations in different forest tree species of Hazarikhil forest of Chittagong, Bangladesh. Journal of Forestry Research, 23(1): 115"122 (2012).

5. Evelin, H., R. Kapoor and B. Giri. Arbuscular mycorrhizal fungi in alleviation of salt stress: A review. Ann Bot.104: 1263-80 (2009).

6. Gerdemann JW, Nicolson TH. Spores of mycorrhizal Endogone extracted from soil by wet sieving and decanting. Trans $\mathrm{Br} \mathrm{Mycol}$ Soc, 46: 235-244 (1963).

7. Guo, H., X. He and Y. Li. Spatial distribution of arbuscular mycorrhiza and glomalin in the rhizosphere of Caragana korshinskii Kom in the Otindag sandy land, China. Afric. J. Microbiol. Res., 6: 5745-5753 (2012).

8. Huq and Alam, A handbook on analyses of soil, plant and water.BACER-DU, University of Dhaka, Bangladesh, 246 (2005).

I. Ortas, 2008. Field trials on mycorrhizal inoculation in the eastern Mediterranean horticultural region. In: Mycorrhiza works (Feldmann F., Kapulnýk Y., Baar J., eds). Hannover, Germany. pp 56-77.

I. Ortas, Effect of mycorrhiza application on plant growth and nutrient uptake in cucumber production under field conditions, Spanish Journal of Agricultural Research 8(S1):S116S122 (2010).

9. J. Beltrano, M. Ruscitti, M.C.Arango and M. Ronco. Effects of arbuscular mycorrhiza inoculation on plant growth, biological and physiological parameters and mineral nutrition in pepper grown under different salinity and p levels, Journal of Soil Science and Plant Nutrition, 13(1), 123-141 (2013).

10. Jiang, W., G. Gou and Y. Ding. Influences of arbuscular mycorrhizal fungi on growth and mineral element absorption of chenglu hybrid bamboo seedlings. Pak. J. Bot., 45(1): 303310 (2013).

11. Junli Hu, Jintian Li, Fuyong Wu, Shengchun Wu, Zhihong Ye, Xiangui Li, Ming Hung Wong. Arbuscular mycorrhizal fungi induced differential $\mathrm{Cd}$ and $\mathrm{P}$ phytoavailability via intercropping of upland kangkong (Ipomoea aquatica Forsk.) with Alfred stonecrop
(Sedum alfredii Hance): postharvest study. Environmental Science and Pollution Research, 20(12): 84578463 (2013).

12. Liu A, Hamel C, Elmi A, Costa C, Ma $\mathrm{B}$, Smith DL. Concentrations of $\mathrm{K}, \mathrm{Ca}$ and $\mathrm{Mg}$ in maize colonized by arbuscular mycorrhizal fungi under field conditions. Can. J. Soil Sci. 82(3): 271-278 (2002).

13. Miller, R.M. and J.D. Jastrow. Vesicular arbuscular mycorrhizae and biogeochemical cycling, pp. 189-212. In:Mycorrhizae and Plant Health.(Eds.): F.L. Pfleger and R.G. Linderman. APS Press, The American Phytopathological Society, St. Paul, Minnesota (1994).

14. Milton Halder, A.S.M Mahmud, Md. Sadiqul Amin, Seikh Mohammad Fazle Rabbi, Faridul Islam, Md. Saidur Rahman, Nemai Chandra nandi, Nusrat Jahan Mouri, Sunuram Ray, Jagadish Chandra Joardar. Effects of iron dust on arsenic accumulation and nutrient status of Ipomoea aquatica grown in arsenic contaminated soil. Research journal of soil Biology, 6(1):17-24 (2014).

15. Phillips, J.M. \& Hayman, D.S. Improved procedures for clearing roots for rapid assessment of infection. Transactions of British Mycological Society, 55:158-161 (1970).

16. Singh A-P, Sumit C, Tripathi M-K, Singh S. Growth and yield of green gram [Vignaradiata(L.) Wilczek] as influenced by biofertilizer and phosphorus application. Hisar, India Agric. Biol. Publishers. Ann. Biol. 20(2): 227-232 ((2004).

17. Smith, S.E. and D.J. Read. Mycorrhizal symbiosis. 3rd ed. San Diego, CA, USA: Academic Press (2008).

18. Tabassum Yaseen, Tanvir Burni and Farrukh Hussain, Effect of arbuscular mycorrhizal inoculation on nutrient uptake, growth and productivity of cowpea (Vignaunguiculata) varieties. African Journal of Biotechnology, 10(43): 8593-8598 (2011).

19. Tonin, C.P., E.J. Vandenkoornhuyse, J. Joner Straczek and C. Leyval. Assessment of arbuscular mycorrhizal fungi diversity in the rhizosphere of Viola calaminaria and effect of these fungi on heavy metal uptake by clover. Mycorrhiza, 10: 161-168 (2001). 
20. Y. Carreon-Abud, E soriano-Bello and M. Martinez- Trujillo. Role of arbuscular mycorrhizal fungi in the uptake of phosphorus by micropropagated blackberry (Rubusfruticosus var. brazos) plants. First
International Meeting on Microbial Phosphate Solubilization, Velazquez, E., RodriguezBarrueco, C. (Eds.), Developments in Plant and Soil Sciences, 102:161-165 (2003). 